\title{
O-Factor Analysis of Mood Ratings
}

\author{
Bo Edvardsson \\ University of Örebro \\ Jan Vegelius \\ University of Uppsala
}

variables. More extensive definitions of methodology are given by Cattell $(1951,1952)$ and Gorsuch (1974, pp. 277-283).

The purpose of this study was to demonstrate the usefulness of $\boldsymbol{O}$-factor analysis in studying how feelings are structured and how situational factors influence feelings.

\section{Methodology}

In a typical factor analysis ( $R$-type) variables are correlated across individuals, resulting in a set of factors "explaining" the most essential part of the variation of the variables. Differences between individuals are fundamental here. In many psychological situations, however, such differences are not too essential. Within clinical psychology, for instance, progress has often been made from intensive studies of individual cases or very few cases (cf. Dukes, 1965; Lawlis, 1976). One way to study quality of life from the aspect of how human beings feel (cf. Edvardsson \& Vegelius, 1976) is that of intensive case studies. A statistical method that seems useful for this is $O$-factor analysis. In this method an analysis is made on data from many variables with only one individual who is measured on several occasions. The occasions are then correlated across the

APPLIED PSYCHOLOGICAL MEASUREMENT Vol. 5, No. 4, Fall 1981, pp. 459-465

(C) Copyright 1981 Applied Psychological Measurement Inc. 0146-6216/81/040459-07\$1.35
Self-ratings of mood were collected from a heterogenous group of four people. Each person was instructed to select the mood-rating words he or she wanted to use, if any, from a list of examples with 287 words in alphabetical order and to add any other words he or she wanted to use. Subjects were instructed to select a list of at least 30 words, to avoid synonyms, and to choose words that described feelings which varied between situations. From these lists an individual rating questionnaire was constructed for each person.

One important observation was that the four subjects chose very different sets of words for self-ratings of mood. The subjects, who were paid for participating, were instructed to use the rating scale questionnaires in different situations (at least 20) during a time period of a few months. They were also requested to write down date, time of the day, environmental characteristics, and other things of importance immediately 
after filling out a questionnaire. Ratings on all variables were measured with a ruler on a scale from 0 to $120 \mathrm{~mm}$ (all rating lines were $120 \mathrm{~mm}$ ), counting from the left side of the scale (strongly agree $=0 \mathrm{~mm}$, strongly disagree $=120 \mathrm{~mm}$ ). As a measure of the similarity between the occasions across "moods" Cohen's $r_{c}$ (Cohen, 1969) was used. It is defined as

$$
r(j, k)=\frac{\sum_{i=1}^{m}\left(x_{i j}-c\right)\left(x_{i k}-c\right)}{\sqrt{\sum_{i=1}^{m}\left(x_{i j}-c\right)^{2}} \sqrt{\sum_{i=1}^{m}\left(x_{i k}-c\right)^{2}}}
$$

where

$$
\begin{aligned}
& j \text { and } k \text { symbolize the two occasions com- } \\
& \text { pared, } \\
& \begin{aligned}
x_{i j} & =\text { rating of "mood" } i \text { on occasion } j, \\
m & =\text { number of moods, and } \\
c & =\text { neutral value of the scale }(=60 \mathrm{~mm}) .
\end{aligned}
\end{aligned}
$$

This coefficient is invariant over variable reflection. If, for example, variable 1 in Table $1 \mathrm{had}$ been reversed (i.e., the word "active" had been changed into its opposite, "passive," and subject A had changed his rating accordingly), Cohen's $r_{c}$ would not change (cf. Holley \& Guilford, 1964).

Vegelius (1978) showed that Cohen's $r_{c}$ is an $E$ correlation coefficient, i.e., it satisfies the requirements of the scalar product between normalized vectors in a Euclidean space. This means that an $O$-analysis may be based on $r_{c}$. By an $\mathrm{O}$-analysis is meant a truncated components analysis of situations across variables for one particular person. In the diagonal of the "correlation" matrix the value 1.0 was thus used. (For further details see Vegelius and Edvardsson, 1979, and Gorsuch, 1974.)

For each one of the four subjects the Cohen $r_{c}$ indices were computed by the CORALL program (Vegelius, 1975), after which $O$-analyses were done by the BMD08M program (Dixon, 1971) with oblique rotations (simple loadings). All analyses from 2 to $n$ factors were made where $n=$ number of eigenvalues above 1 . The solu- tions with the best psychological interpretations are presented below. The factors were interpreted by the free descriptions and by the scores on the moods for the situations with the highest factor loadings.

\section{Results $^{1}$}

\section{Subject A}

To illustrate the type of data used, Table 1 shows the 32 mood descriptions chosen by Subject $A$, a male student of theology at the University of Uppsala, 26 years oid. He rated his feelings on the 32 mood-rating scales on the 29 occasions described in Table 2. The Cohen $r_{c}$ indices between the 29 occasions were computed, and the following six eigenvalues were above 1: 10.17, 4.65, 3.12, 1.69, 1.19, and 1.09. According to the Kaiser criterion (Kaiser \& Caffrey, 1965), six factors should be retained. However, the number of factors was reduced so that only strong factors, which accounted for very typical situations, were considered. In this case, two factors accounting for $51 \%$ of the "variance" seemed to give the best psychological interpretation.

The rotated factor matrix for Subject A is shown in Table 3. Using the verbal descriptions of the student and his results, the factors were interpreted as follows:

\section{Satisfaction}

Situations: where something has just been successfully finished, e.g., having just studied a book, having just packed before a journey, having just passed an exam, having returned home after an intensive holiday.

Feelings: e.g., happy, alone, passive, not aggressive, not guilty, not irritated.

II. Stress

Situations: e.g., at midnight after having studied for many hours without having

'Tables of raw-data for the subjects' ratings on each occasion, $\boldsymbol{O}$-correlation matrices, and factor matrices are available from the authors. 


\section{Table 1}

The 32 Moods Chosen by Subject A, After the phrase: "Just now I feel . . ." (Swedish translation in parentheses.)
1. aggressive (aggressiv)
2. like rejecting (avståndstagande)
3. efficient (effektiv)
4. egoistical (egoistisk)
5. lonely (ensam)
6. puzzled (frågande)
7. fellowship (gemenskap)
8. contact with God (gudskontakt)
9. have acquired knowledge (ha fătt insikter)
10. inspired (inspirerad)
11. interested (intresserad)
12. ironic (ironisk)
13. irritated (irriterad)
14. edgy (kantig)
15. critical (kritisk)
16. indifferent (likgiltig)
17. happy (lycklig)
18. melancholy (melankolisk)
19. pleasure-seeking (nöjeslysten)
20. uncertain (osäker)
21. passive (passiv)
22. restless (rastlös)
23. sentimental (sentimental)
24. sensual (sinnlig)
25. guilty (skuldmedveten)
26. like laughing (skratt)
27. I am participating (som deltagare)
28. I am a spectator (som åskådare)
29. spontaneous (spontan)
30. under pressure (stressad)
31. inferior (underlägsen)
32. open (öppen)

finished his task, thinking a lot of future studying.

Feelings: e.g., stress, irritated, insecure, not sentimental.

For the other three persons only the major results will be given.

\section{Subject B}

Subject B was a 32-year-old male psychologist. He used 61 mood-rating words on 32 occasions, both work and leisure situations. A four-factor solution accounting for $70 \%$ of the "variance" seemed to give the best interpretations. The factors had very low intercorrelations and were labeled as follows:

\section{Euphoria}

Situations: e.g., on vacation on a beautiful island, sitting on a rock at the sea, sitting alone relaxed, after running and a shower, getting a new job, listening to classical music, sunshine and birds.

Feelings: e.g., alone, developing, experiencing beauty, thoughtful, resolute will to live, involved, melting with nature, experiencing infinity, harmonious, belongingness.

II. Dysphoria: strong psychological

Situations: e.g., after criticism, sitting in a car after camping out with mosquitos, sitting sleepily in a car, after food-sickness, alone in a tent with unpleasant thoughts.

Feelings: e.g., tired, irritated, depressed, isolated, tense, filled with problems, alone.

III. Dysphoria: psychosomatic

Situations: e.g., after hard work and insufficient sleep, work to do, working too long without a pause.

Feelings: e.g., headache, exhausted, tired, irritated, pressed, depressed.

IV. Dysphoria: mild psychological

Situations: e.g., lying on a bed after ordinary work, after conference with staff, sitting on a train.

Feelings: e.g., somewhat tired, lack of enthusiasm, disappointed. 
1. June 30. Time 21.00. At a desk in a bedroom. Have worked all day. Sort of tired. Hot.

2. July 1. Time 12.10. Lunchroom at father-in-law's firm. Together with co-workers I vaguely know. After a high-pressure morning, but an independent job. Everyone a bit irritated as badly organized vacations draw near.

3. July 2. Time 6.30. At my sister's house. Just woke up. Alone. A new working day to come.

4. July 8. Time 12.20. Lunchtable at my place of work. Somewhat annoyed at the engineer, who is not a good organizer. Cloudy and rainy after extremely hot weather.

5. July 16. Time 14.50. Alone at my sister's house. Have studied theology the whole day long.

6. July 19. Time 12.00. On a job at a nearby town. My companion and I discussed God and the use of clergymen on the way there. Sunny. $30^{\circ}$ centigrade in the car.

7. July 20. Time 11.00. At father-in-law's house. Have the day off in order to study, that is, they don't have anything for me to do and so I get a "study day." Too hot weather.

8. July 30. Time 20.00. In Uppsala, packing for a trip to Thailand. Nice to be at home. Only my wife. No noise.

9. Aug. 2. Time 9.15. At home. Everything is ready for the trip to Thailand.

10. Aug. 3. Time 19.50 (local time). At hotel in Singapore due to strike at Bangkok's airport. Awfully warm with high humidity. Have just eaten (good food and a lot of it)!

11. Aug. 25. Time 20.25. Home after Thailand trip. Everything is silent and wonderful. Tired but healthy. Two friends have visited us.

12. Aug. 28. Time 11.30. Pre-weekend silence. Listening to a phonograph record which creates a pleasant mood.

13. Sept. 1. Time 9.40. At the University. Registration and information. More than 100 people in the room. Thrilling and expectant.

14. Sept. 3. Time 10.30. Greek lessons. 80 students, happy, a bit nervous. The form of examination is being discussed right now.

15. Sept. 5. Time 18.50. Lots of work waiting, which means that nothing gets done.

16. Sept. 12. Time 11.00. Greek lessons. Pause. Autumn chill. Scattered voices.

17. Oct. 4. Time 10.00 Lots of work. Rather fun. Alone at home after an intensive weekend spent on a doctoral disputation in Uppsala and visiting relatives in other towns.

18. Oct. 11. Time 12.30. Studying Greek with a friend. Wife is preparing dinner. Hungry.

19. Oct. 15. Time 10.30. Greek lessons. Many students feel tired and overworked. So do I.

20. Oct. 20. Time 23.55. Alone. Wife is sleeping. Uncertain whether to read more or not. Probably not. Tired in more than one way. Have answered the 32 questions from 32 to 1 . Feels better that way.

21. Oct. 21. Time 10.05. At home. Wife is dusting. Feel worried that I won't get time to study enough to pass the exam.

22. Oct. 22. Time 13.06. Two hours after examination. Turned out well, I think. My brother and his girl friend have arrived.

23. Nov. 8. Time 11.00. Have passed my exam. Have had a nice weekend. Have begun thinking of new work. Pleasantly tired. Niece is visiting us.

24. Nov. 17. Time 8.30. Alone at home. Greek is finished now. Church history to come. Have lots to do.

25. Nov. 22. Time 14.40. Yesterday was my wife's birthday. Thinking of future. Wife is sleeping.

26. Nov. 29. Time 7.30. Alone at home. My wife is sleeping. I begin to study literature course. Feels all right.

27. Dec. 6. Time 11.50. Alone at home listening to silence. Preparing a party for the students at the same house.

28. Dec. 13. Time 11.35. Alone at home after having been honored by two Lucia-choirs (Swedish tradition) early in the morning with song and cakes. Half of last week's job is left.

29. Dec. 15. Time 16.00. Have finished a course book three days late. Alone. A party is just about to start. 
Table 3

Rotated Factor Matrix from

the 0-Analysis for Subject $A$

(Factor Intercorrelation $=.136$ )

\begin{tabular}{|c|c|c|}
\hline Occasion & Factor 1 & Factor 2 \\
\hline 1 & .173 & -.026 \\
\hline 2 & .156 & .472 \\
\hline 3 & -.272 & .121 \\
\hline 4 & -.088 & .383 \\
\hline 5 & .019 & .661 \\
\hline 6 & .286 & .279 \\
\hline 7 & .322 & .444 \\
\hline 8 & .937 & -.107 \\
\hline 9 & .750 & .263 \\
\hline 10 & .686 & .405 \\
\hline 11 & .303 & .112 \\
\hline 12 & .754 & -.206 \\
\hline 13 & .521 & .517 \\
\hline 14 & .623 & .367 \\
\hline 15 & -.112 & .748 \\
\hline 16 & .707 & .360 \\
\hline 17 & .240 & .539 \\
\hline 18 & .715 & -.018 \\
\hline 19 & .213 & .811 \\
\hline 20 & -.346 & .813 \\
\hline 21 & .667 & .402 \\
\hline 22 & .761 & .001 \\
\hline 23 & .832 & -.079 \\
\hline 24 & -.268 & .752 \\
\hline 25 & .658 & -.417 \\
\hline 26 & .618 & .113 \\
\hline 27 & .750 & .086 \\
\hline 28 & .863 & -.145 \\
\hline 29 & .902 & -.237 \\
\hline
\end{tabular}

\section{Subject C}

Subject C, a 54-year-old female pensioner with 7 years of schooling, used 30 mood-rating scales on 27 occasions. A three-factor solution accounting for $69 \%$ of the "variance" seemed to give the best interpretations. Factors had negligible correlations except for Factors I and III, which had a moderate correlation. Factors were labeled as follows:

\section{Social communion}

Situations: e.g., visiting daughter and granddaughter, drinking coffee with sister, drinking coffee with old schoolfellow.

Feelings: e.g., alert, interested, human, primitive.

\section{Annoyance}

Situations: e.g., cannot sleep and is reading, visiting the dentist, cannot sleep because of noise, sick, warm and thirsty.

Feelings: e.g., tired, powerless, forced, anxious.

\section{Harmony}

Situations: e.g., in the church at a divine service, her birthday, visiting her sister at a camping-ground, sitting at a small leisure boat harbor, bathing.

Feelings: e.g., harmonious, aware, interested, humble, welcome.

\section{Subject D}

Subject D was a 27 -year-old male, a graduate in law, working as a journalist. He used 43 mood-rating scales on 29 occasions. A three-factor solution accounting for $72 \%$ of the "variance" seemed to give the best interpretations. Factor intercorrelations were small except between Factors I and III, where there was a moderate correlation. Factors were labeled as follows:

\section{Activity}

Situations: e.g., working hard, has done a lot, much to do, visiting a family who have lost their daughter recently, impressions from the environment around a public speech by the prime minister.

Feelings: e.g., active, hard-working, avoiding, happy, of use, belongingness.

\section{Low mood}

Situations: e.g., sick, nothing works in his job, the wrong parties won the elections.

Feelings: e.g., tired, unable, exhausted. 


\section{Satisfaction}

Situations: e.g., has learned a lot at work, leisure time, visiting parents, sitting at breakfast table in sunshine.

Feelings: e.g., will to live, happy, cheerful, belongingness, enthusiastic.

\section{Discussion}

People structure their time with feelings in different ways according to their psychological patterns. They seek different situations and are programmed to feel in different ways in similar environments. The method presented here, where people select the feeling variables which they consider would be relevant and select situations in which to rate feelings seems highly relevant to study emotional functioning in everyday life, i.e., the subjective quality of life. This method can be contrasted with studies where each person uses a standardized scale and is pressed into the same structure as other people (which, of course, has advantages for some purposes). The $O$-factor analytical technique takes care of the uniqueness of each human being - an essential aim of especially humanistic psychology. Of course, other statistical methods and measures may also be valuable for this kind of data. Commenting on the four illustrative cases, it is evident that all three had at least one positive ("good mood") factor and at least one negative ("bad mood") factor. This seems reasonable for emotionally healthy individuals. The emotional functioning of Subject B seems to be in need of change through personality change and/or change of environments. Another study after change of work could give evidence of and define change in Subject B's emotional life.

There are a number of possible applications of the method presented in this paper. It is probable that the method can be used to study individual differences in a more thorough way than the common approaches using $R$-type analysis. Perhaps typical patterns can be found. This method can be used in studies of the quality of life of different jobs and of the lives of pen- sioners-institutionalized people and psychiatric patients, for example. The method can perhaps clarify clinical diagnoses. An area of application that seems highly relevant is the study of change processes in psychotherapy (an important quality of life area) where change can be studied in several ways, e.g., by comparing selection of self-descriptive words at different points in therapy, by comparing factor scores or means and variances on composite scales constructed to measure the factors, or by comparing factor structures with or without change of self-rating words. Thorough studies of individual change processes can probably extend knowledge of how different psychotherapy methods affect people much more than common group studies. This method may be more sensitive to change and can define change in a more detailed way than standardized scales.

There are two problems with using the method presented in this paper. One problem is that the individual's selection of situations can bias the results. It is difficult to determine representativity. On the other hand, the individual's selection reflects his or her personality, i.e., a change in factor structure dependent on selection of different situations probably reflects some personality change. Instructions to select situations of different kinds should thus be given. Another problem is that for mathematical reasons it is necessary that the number of rating variables exceed the number of occasions for each subject. If it is desired to use more occasions than rating variables, the data can be divided into two or more parts and each can be $\boldsymbol{O}$-factor analyzed. This could be done for validation purposes.

\section{References}

Cattell, R. B. On the disuse and misuse of $P, Q, Q$ and $O$ techniques in clinical psychology. Journal of Clinical Psychology, 1951, 7, 203-214.

Cattell, R. B. The three basic factor-analytic research designs-Their interrelations and derivatives. Psychological Bulletin, 1952, 49, 499-520.

Cohen, J. $r_{c}$ : A profile similarity coefficient invariant over variable reflection. Psychological Bulletin. $1969,71,281-284$. 
Dixon, W. J. Biomedical computer programs (2nd ed.). Berkeley: University of California Press, 1971.

Dukes, W. F. $N=1$. Psychological Bulletin, 1965, 64, 74-79.

Edvardsson, B., \& Vegelius, J. Livskvalitet (Forskningsrapport nr 132). Stockholm: Religionssociologiska institutet, 1976.

Gorsuch, R. L. Factor analysis. Philadelphia: Saunders, 1974.

Holley, J. W., \& Guilford, J. P. A note on the $G$ index of agreement. Educational and Psychological Measurement, 1964, 24, 749-753.

Kaiser, H. F., \& Caffrey, J. Alpha factor analysis. Psychometrika, 1965, 30, 1.

Lawlis, G. F. Multivariate methodology for $N=1$. Multivariate Experimental Clinical Research. 1976, 2, 101-106.

Vegelius, J. CORALL, a FORTRAN IV program for correlation measures. Educational and Psychological Measurement. 1975, 35, 711-712.
Vegelius, J. On the utility of the $E$-correlation coefficient concept in psychological research. Educational and Psychological Measurement, 1978, 38. 605-611.

Vegelius, J., \& Edvardsson, B. On the use of the $G$ index in $O-, P-, Q-, R-, S$ - and $T$-analyses. Educational and Psychological Measurement, 1979, 39, 707-710.

\section{Acknowledgments}

This research was supported by the Swedish Research Council in the Humanistic and Social Sciences.

\section{Author's Address}

Send requests for reprints or further information to Jan Vegelius, Department of Statistics, P.O. Box 513, S-75120 Uppsala, Sweden. 